\title{
THE EFFECT OF POWDER BALL MILLING ON THE MICROSTRUCTURE AND MECHANICAL PROPERTIES OF SINTERED Fe-Cr-Mo-Mn-(Cu) STEEL
}

\author{
P. Kulecki, E. Lichańska
}

\begin{abstract}
The effect of ball milling powder mixtures of Höganäs pre-alloyed iron Astaloy CrM, low-carbon ferromanganese Elkem, elemental electrolytic $\mathrm{Cu}$ and $\mathrm{C}-U F$ graphite on the sintered structure and mechanical properties was evaluated. The mixing was conducted using Turbula mixer for 30 minutes and CDI-EM60 frequency inverter for 1 and 2 hours. Milling was performed on $150 \mathrm{~g}$ mixtures with (in weight \%) CrM $+1 \%$ $\mathrm{Mn}, \mathrm{CrM}+2 \% \mathrm{Mn}, \mathrm{CrM}+1 \% \mathrm{Mn}+1 \% \mathrm{Cu}$ and $\mathrm{CrM}+2 \% \mathrm{Mn}+1 \%$ $\mathrm{Cu}$, all with $0.6 \% \mathrm{C}$. The green compacts were single pressed at $660 \mathrm{MPa}$ according to PN-EN ISO 2740. Sintering was carried out in a laboratory horizontal furnace Carbolite STF $15 / 450$ at $1250^{\circ} \mathrm{C}$ for 60 minutes in $5 \% \mathrm{H}_{2}-95 \% \mathrm{~N}_{2}$ atmosphere with a heating rate of $75^{\circ} \mathrm{C} / \mathrm{min}$, followed by sintering hardening at $60^{\circ} \mathrm{C} / \mathrm{min}$ cooling rate. All the steels were characterized by martensitic structures. Mechanical testing revealed that steels based on milled powders have slightly higher mechanical properties compared to those only mixed and sintered. The best combination of mechanical properties, for ball milled CrM $+1 \% \mathrm{Mn}+$ 1\% Cu was UTS $1046 \mathrm{MPa}$, TRS $1336 \mathrm{MPa}$ and $\mathrm{A}$ 1.94\%.
\end{abstract}

Keywords: Ball milling, mechanical properties, Astaloy CrM, microstructure, sinter-hardening, copper

\section{INTRODUCTION}

Mechanical bonding of particles by milling in ball mill was originally developed for the aerospace industry. The first materials were designed as oxide-dispersion strengthened nickel and iron-base superalloys. Mechanical milling could be provided in different types of ball mills, but the most popular instruments for such a processing are high energy ball mills. The direct results of processing powder in ball mill are reducing the particle size and blending of particles in new phases. Because of economical aspect of this processing large scale production should be conducted. The formation process of new phases is strictly related to many milling variables $[1,2]$. Mechanical milling involves repeated processes such as: welding, fracturing and rewelding of powder particles. The kinetic of changes in milling powder are inducted by the total amount of energy transferred from balls to the powder particles during milling. The energy transfer depends on such parameters: type of ball mill, milling speed, powder mass to ball mass ratio, lubricant presence, ball filling rate of milling container, milling speed, time and temperature of process $[3,4]$. 
Rising temperature during milling induces diffusion of mass and concentration of defects influencing on phase transformation during this process. Applying this type of powder processing could result in the formation of nanocrystalline phases also [5-7]. During the mechanical milling process, milled powder can be contaminated because of the impurities of the starting powders, milling equipment (drum and grinding medium), atmospheric impurities and milling atmosphere. Among all the impurities, the effect of oxygen is significant and causes formation of oxides which isolate pure areas of particles and make difficult sinterability [8,9].

\section{SCOPE OF THE RESEARCH}

To evaluate the effect of mechanical milling process on the mechanical properties and microstructure of research PM steels followed investigations were made:

- $\quad$ specified technological properties of processed powder,

- height measurement of greens,

- measurement of density by the geometrical method,

- assignation of ultimate tensile strength, yield strength and transrupture strength,

- assignation of elongation,

- measurement of hardness HV 30,

- $\quad$ evaluation of microstructure and fractography of researched steels.

Sieve analysis and flow rate were carried out according to ISO 4497 norm. Bulk density and tap density occurred, according to norms ISO 3923-2 and ISO 3923-1 respectively. Tensile strength test made on endurance machine MTS. Parameters of the tensile test defined in accordance with standard PN-EN 10002-1. Moving speed of the traverse was $1 \mathrm{~mm} / \mathrm{min}$. Cross-breaking strength test made on endurance ZD10. During bending sample was on cylindrical supports distant $28.6 \mathrm{~mm}$. Bending force work on the sample's surfaces which during pressing press upper punch. Metallographic research was an additional analysis of mechanical properties and made on metallographic section prepared according to procedure consist in position [10]. After sending and polishing, surfaces of metallographic section were etched 3\% natal. Observations of a structure made on a Leica DM4000M optic microscope using bright field (BF) technique. Total zoom of the microscope was 500x. For fracture research used scanning transmission electron microscope (SEM) Inspect S50.

\section{MATERIAL AND PREPARATION OF TEST SAMPLES}

The output powders used for research were: Astaloy CrM prealloyed iron powder made by Höganäs, ferromanganese master alloy Elkem $(77 \% \mathrm{Mn})$, electrolytic copper powder and carbon in the form of graphite - ultra fine.

According to Table 1 several mixtures were prepared based on different chemical composition and powder processing. Mixtures consist in \% mass: Astaloy $\mathrm{CrM}+1 \% \mathrm{Mn}+$ $0.6 \% \mathrm{C}$ marked as A, Astaloy CrM $+2 \% \mathrm{Mn}+0.6 \% \mathrm{C}$ marked as $\mathrm{B}$, Astaloy CrM $+1 \%$ $\mathrm{Mn}+1 \% \mathrm{Cu}+0.6 \% \mathrm{C}$ marked as $\mathrm{C}$ and Astaloy $\mathrm{CrM}+2 \% \mathrm{Mn}+1 \% \mathrm{Cu}+0.6 \% \mathrm{C}$ marked as D. All powder mixtures were mixed/milled in three ways: in Turbula mixer for $30 \mathrm{~min}$ and in ball mill CDI-EM60 for 60 and 120 min. Mixing and milling were conducted in atmosphere consist air and nitrogen respectively. Milling media were balls made from AISI 52100 steel with a mean diameter of $12 \mathrm{~mm}$. Milling speed was $60 \%$ of critical velocity. Balls mass to feed mass ratio was 12:1. Mixtures based on powders processed in ball mill were milled without carbon which was supplemented by graphite after milling, mixed in Turbula for proper distribute of this element. 
Tab.1. Designation, chemical composition, mixing/milling type and mixing/milling material (*- mixtures milled without addition of carbon)

\begin{tabular}{|l|c|c|}
\hline \multicolumn{1}{|c|}{$\begin{array}{c}\text { Designation and chemical composition of } \\
\text { powders mixtures in } \% \text { mass }\end{array}$} & $\begin{array}{c}\text { Mixing/milling type } \\
\text { and time, min }\end{array}$ & $\begin{array}{c}\text { Mixing/miling } \\
\text { material }\end{array}$ \\
\hline A - Ast. CrM $+1 \% \mathrm{Mn}+0.6 \% \mathrm{C}$ & Turbula, 30 & A, B, C, D \\
\cline { 2 - 3 } B - Ast. CrM $+2 \% \mathrm{Mn}+0.6 \% \mathrm{C}$ & CDI-EM60, 60 & $(\mathrm{~A}, \mathrm{~B}, \mathrm{C}, \mathrm{D}) *$ \\
$\mathrm{C}$ - Ast. $\mathrm{CrM}+1 \% \mathrm{Mn}+1 \% \mathrm{Cu}+0.6 \% \mathrm{C}$ & CDI-EM60, 120 & $(\mathrm{~A}, \mathrm{~B}, \mathrm{C}, \mathrm{D})^{*}$ \\
\hline
\end{tabular}

Following mixing/milling, green compacts in "dog-bone" form were single pressed at $660 \mathrm{MPa}$. Sintering was carried out in a laboratory horizontal furnace at $1250^{\circ} \mathrm{C}$ for 60 minutes in $5 \% \mathrm{H}_{2}-95 \% \mathrm{~N}_{2}$ atmosphere and saturation point at $-60{ }^{\circ} \mathrm{C}$. Colling form sintering temperature was performed using sinter-hardening technique with cooling rate $60^{\circ} \mathrm{C} / \mathrm{min}$.

\section{RESULTS}

\section{Technological properties of based and processed mixtures}

Measurements of technological properties were carried out for mixture A consist in $\%$ mass Astaloy $\mathrm{CrM}+1 \% \mathrm{Mn}+0.6 \% \mathrm{C}$. Figure 1 shows the results of measurements of technological properties. Figure 2 presents sieve analysis of mixtures: mixed in Turbula mixer $(0 \mathrm{~h})$ and processed in ball mill $(1 \mathrm{~h}$ and $2 \mathrm{~h})$.

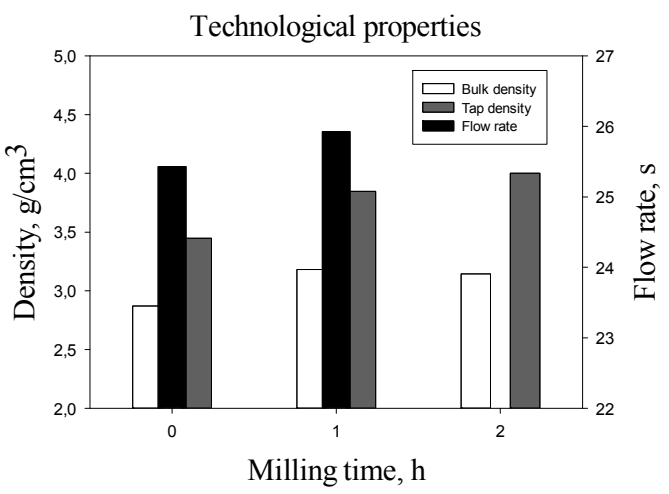

Fig.1. Technological properties of Astaloy $\mathrm{CrM}+1 \% \mathrm{Mn}+0.6 \% \mathrm{C}$ mixture

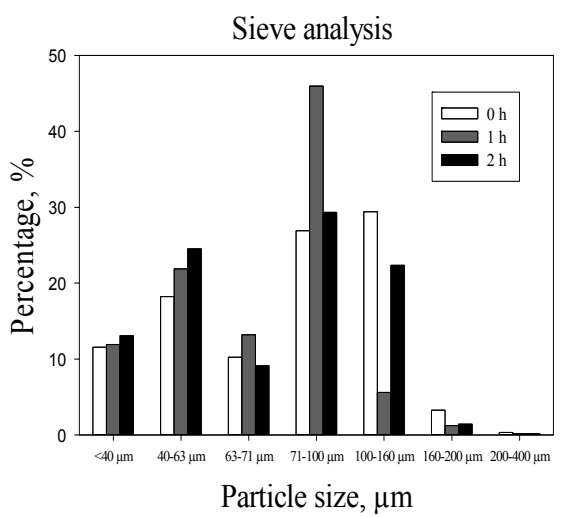

Fig.2. Sieve analysis of Astaloy CrM + $1 \% \mathrm{Mn}+0.6 \% \mathrm{C}$ with processed mixture results

\section{Geometrical dimensions of greens and sinters}

Figures 3 and 4 show mean geometric values of greens - height and density and on Figure 5 is shown density of sinters measured by geometrical method. 


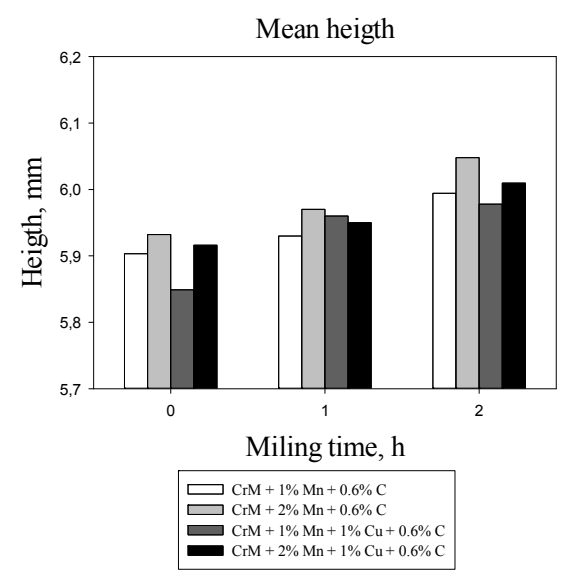

Fig.3. The mean height of greens made on processed powders.

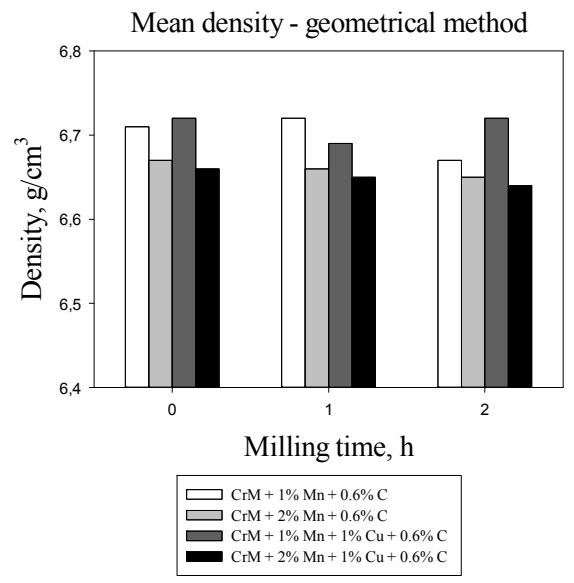

Fig.5. The mean density of sinters measured by the geometrical method.

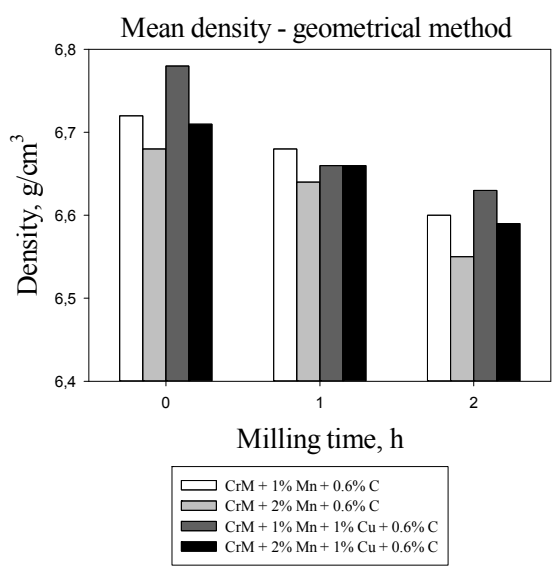

Fig.4. The mean density of greens measured by geometrical method.

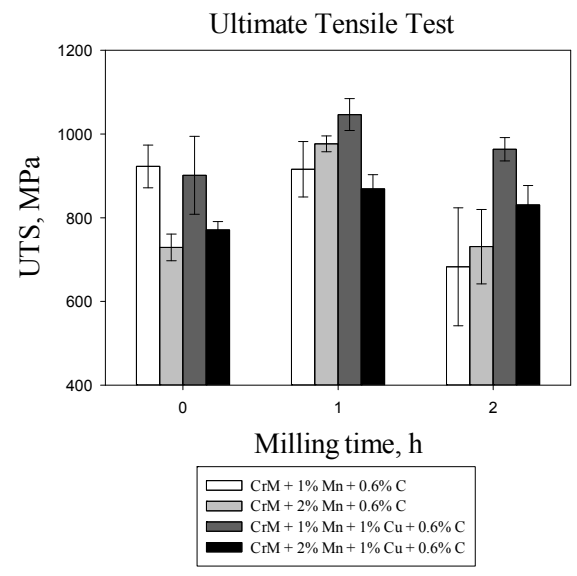

Fig.6. Mean UTS and standard deviation in function of milling time for all researched variants of PM steels.

\section{Mechanical properties, microstructure and fractography of research steels}

Figures 6 and 10 show results of mechanical testing of all researched PM steels ultimate tensile strength, yield tensile strength, transverse rupture strength, elongation and hardness in function of milling time. Graphs present mean values with standard deviation marks. 

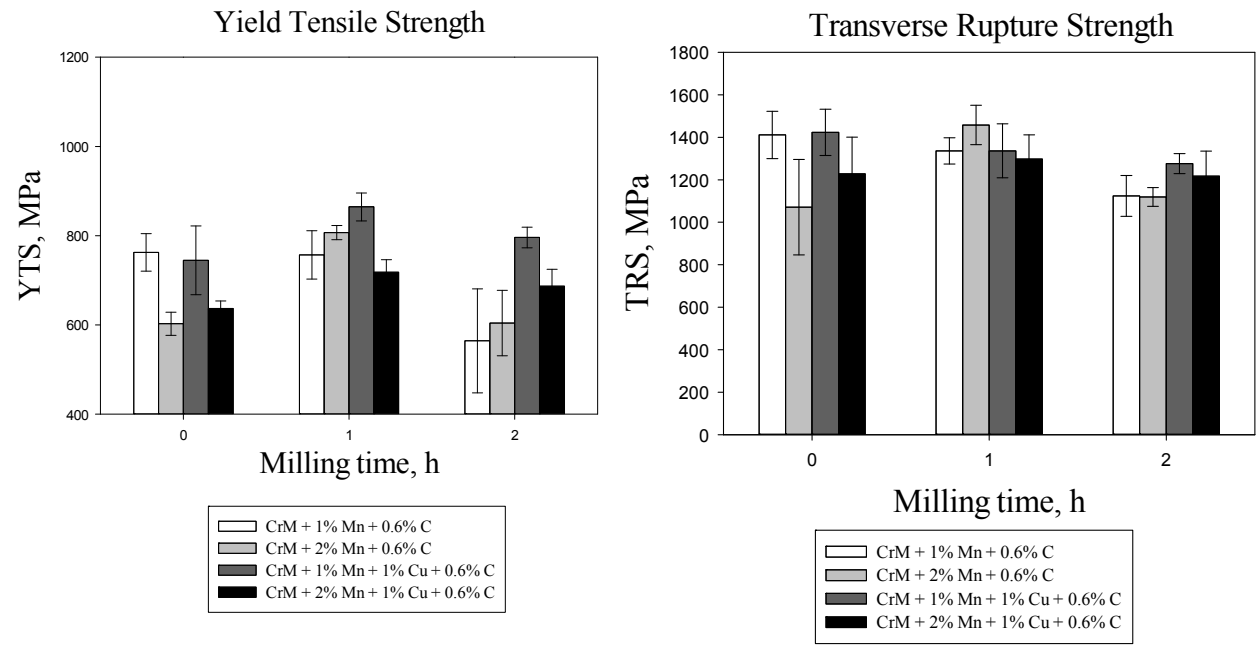

Fig.7. The mean YTS and standard deviation in function of milling time for all researched variants of PM steels.

Fig.8. The mean transverse rupture strength and standard deviation in function of milling time for all researched variants of PM steels.

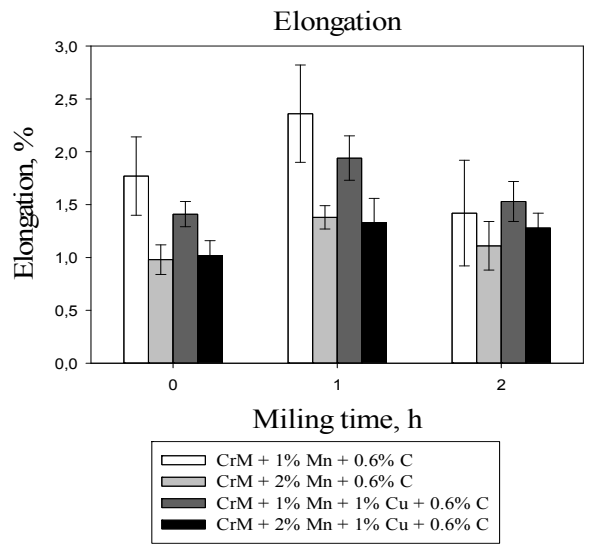

Fig.9. The mean elongation of research PM steels in function of milling time.

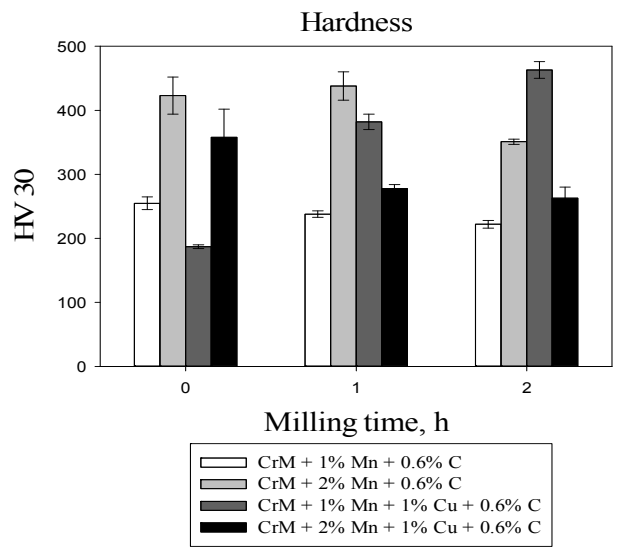

Fig.10. The mean hardness HV 30 of researched PM steels in function of milling time. 


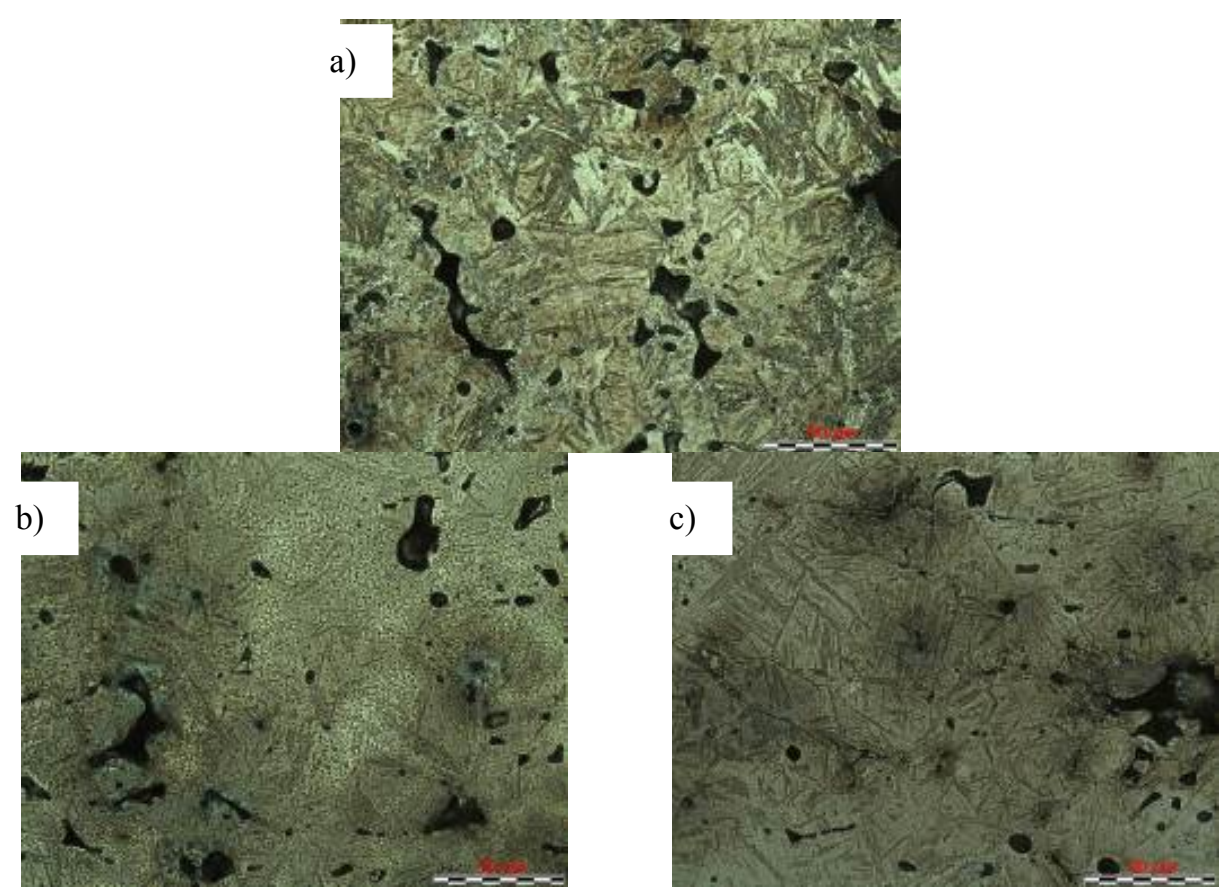

Fig. 11. The characteristic microstructures of $\mathrm{CrM}+1 \% \mathrm{Mn}+0.6 \% \mathrm{C}$ PM steels based on mixed/milled powders for a) $0 \mathrm{~h}$, b) $1 \mathrm{~h}$ and c) $2 \mathrm{~h}-$ marker $50 \mu \mathrm{m}$

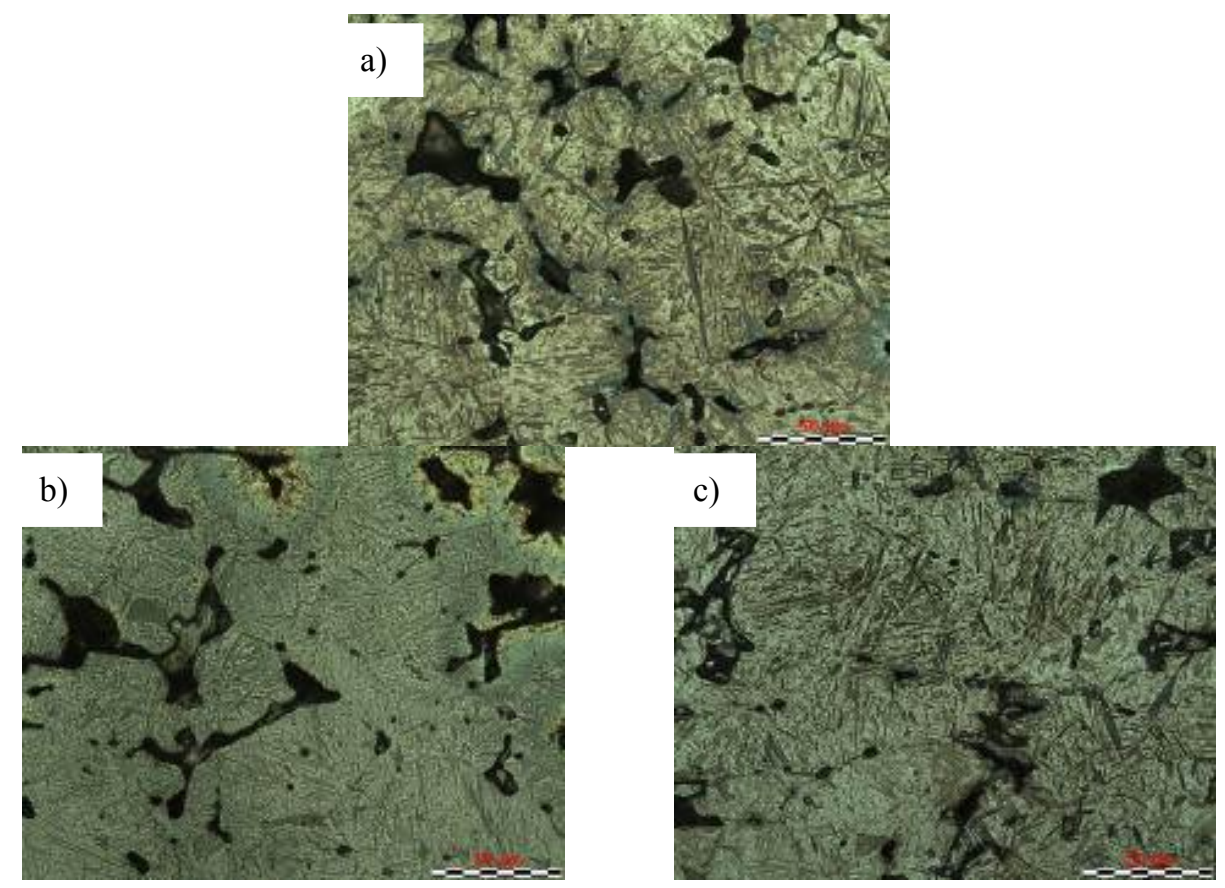

Fig. 12. The characteristic microstructures of $\mathrm{CrM}+2 \% \mathrm{Mn}+0.6 \% \mathrm{C}$ PM steels based on mixed/milled powders for a) $0 \mathrm{~h}, \mathrm{~b}) 1 \mathrm{~h}$ and c) $2 \mathrm{~h}-$ marker $50 \mu \mathrm{m}$. 


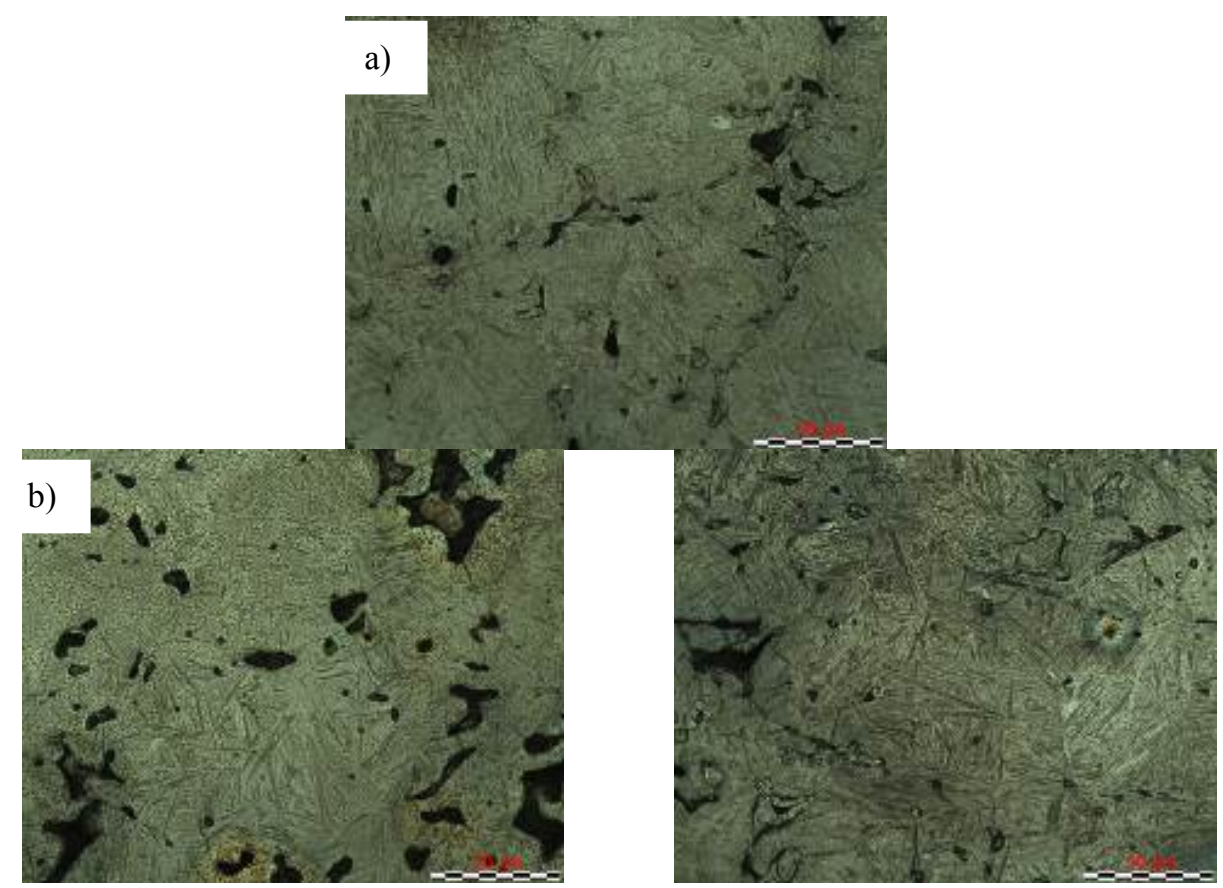

Fig.13. The characteristic microstructures of $\mathrm{CrM}+1 \% \mathrm{Mn}+1 \% \mathrm{Cu}+0.6 \% \mathrm{C} \mathrm{PM}$ steels based on mixed/milled powders for a) $0 \mathrm{~h}$, b) $1 \mathrm{~h}$ and c) $2 \mathrm{~h}-$ marker $50 \mu \mathrm{m}$.

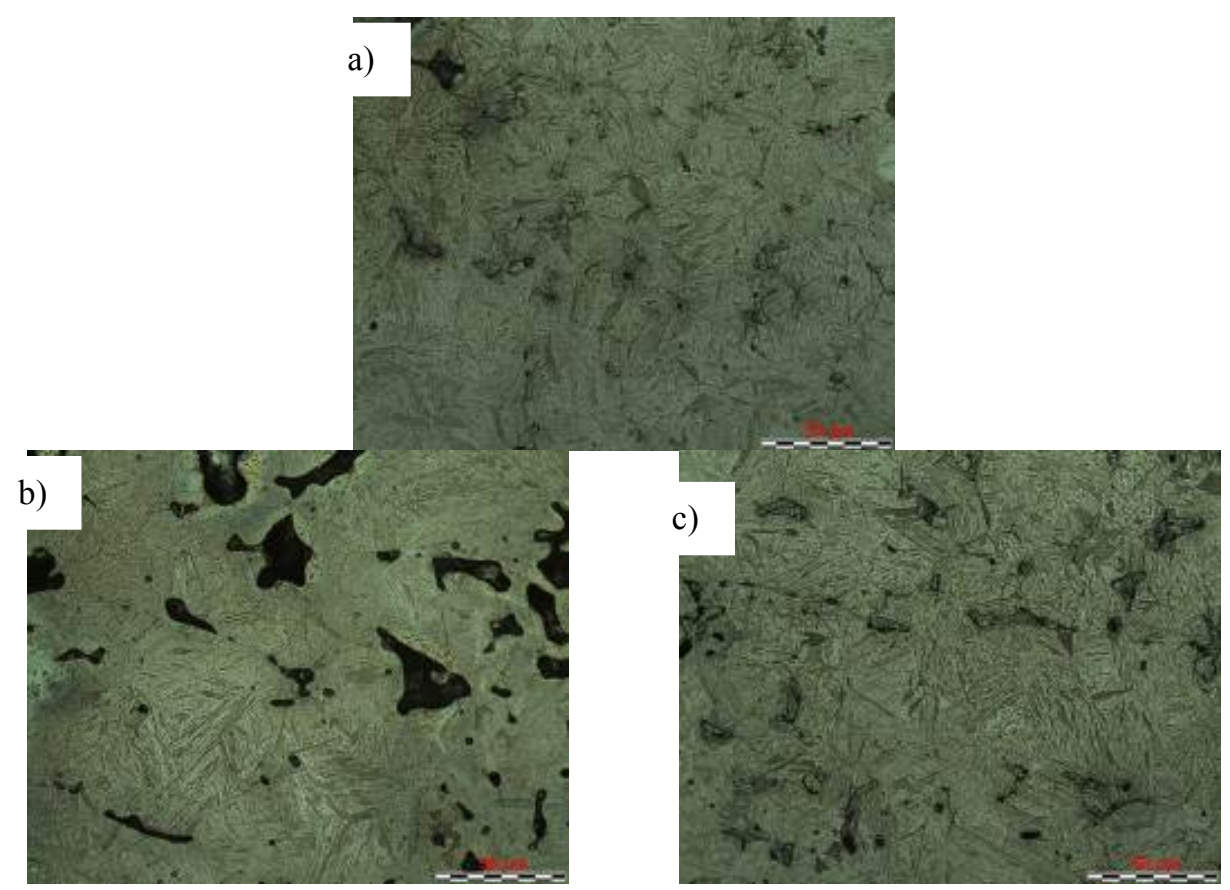

Fig. 14. The characteristic microstructures of $\mathrm{CrM}+2 \% \mathrm{Mn}+1 \% \mathrm{Cu}+0.6 \% \mathrm{C}$ PM steels based on mixed/milled powders for a) $0 \mathrm{~h}$, b) $1 \mathrm{~h}$ and c) $2 \mathrm{~h}-$ marker $50 \mu \mathrm{m}$. 
Figures 11-14 presents characteristic microstructures of all examined PM steels. On Figure 15 is shown fractography of all researched steels variants.

$0 \mathrm{~h}$

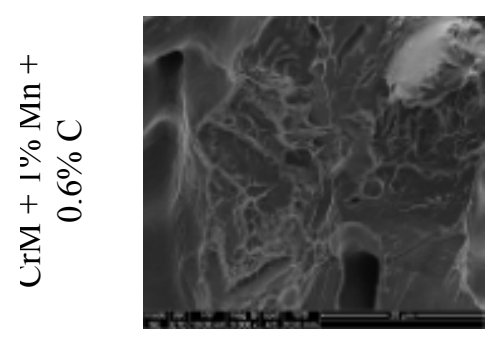

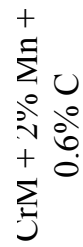

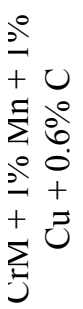

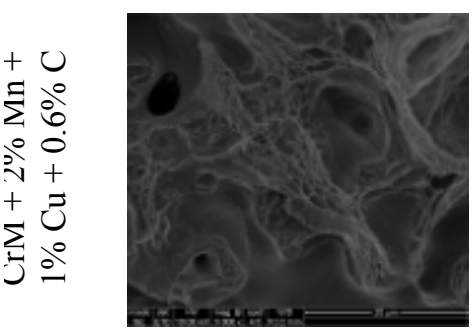

$1 \mathrm{~h}$
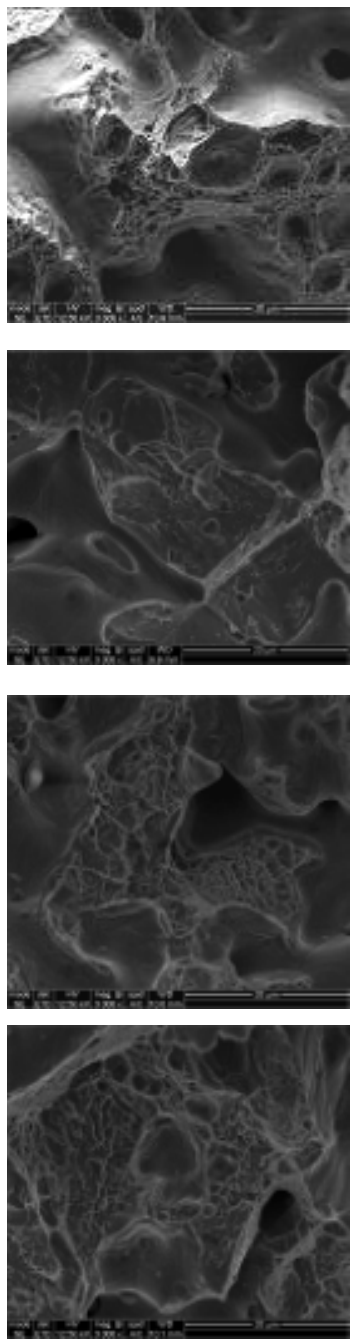

$2 \mathrm{~h}$
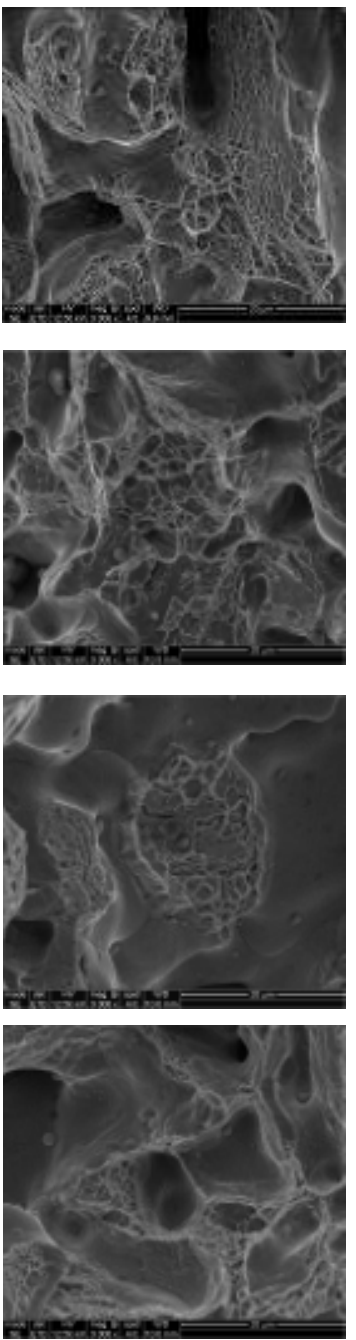

Fig.15. Fractography of all researched PM steels based on different chemical composition and powder processing (SEM) - marker $20 \mu \mathrm{m}$.

\section{DISCUSSION OF RESULTS}

Technological properties data, shown on Fig.1, show that increasing milling time increase from 2.8 to $3.2 \mathrm{~g} / \mathrm{cm}^{3}$ and from 3.5 to $4 \mathrm{~g} / \mathrm{cm}^{3}$ bulk density and tap density, respectively. Milling powder caused the decreasing size of particles and in effect better packing of mixture. It is clearly visible, Fig. 2, that increasing amount of finer size particles is proportional to the time of processing in the ball mill. Because of the prealloyed nature of Astaloy $\mathrm{CrM}$ powder, alloying additions (Cr, Mo) are homogeneously dissolved and 
significant strengthening of ferrite during fast cooling in atomization process. Harder particles have a higher fragmentation rate in comparison to soft pure iron powders.

Increasing time of preparation powder via milling had a significant effect on height and density. During mechanical milling in a ball mill, powder particles decreased and took more spherical shapes which correspond well with [11,12]. The greater share of finer, strain hardened particles of more spherical shape affect compressibility deterioration. Because of the green height increase, density decrease from $\sim 6.7 \mathrm{~g} / \mathrm{cm}^{3}$ to $\sim 6.6 \mathrm{~g} / \mathrm{cm}^{3}$ with milling time. Chemical composition did not affect the height and density of green compacts.

After sintering at $1250^{\circ} \mathrm{C}$, all samples had a uniform density in the range 6.65 to $6.7 \mathrm{~g} / \mathrm{cm}^{3}$. Densification during sintering is clearly visible, especially for steels based on powders processed in the ball mill. Increasing milling time affected strongly density during sintering. Chemical composition slightly affected densification; e.g. substitution $2 \%$ Mn by $1 \% \mathrm{Mn}+1 \% \mathrm{Cu}$ caused increase of density up to $\sim 6.72 \mathrm{~g} / \mathrm{cm}^{3}$. Because the sintering temperature was higher than copper melting point, isothermal hold at $1250^{\circ} \mathrm{C}$ resulted in the formation of $\mathrm{Cu}$ liquid phase, favouring rearrangement of solid particles and higher densification. It is also well visible for steels based on milled mixture Astaloy $\mathrm{CrM}+1 \%$ $\mathrm{Mn}+1 \% \mathrm{Cu}$. Powder processing in the ball mill had a significant influence on the morphology of milled particles, e.g. spheroidization of powder particles. Evolution of particle shapes in this way will promote easier rearrangement during sintering, especially in the presence of a liquid phase. This effect is well seen on Astaloy $\mathrm{CrM}+1 \% \mathrm{Mn}+1 \% \mathrm{Cu}$ based steels, milled for $2 \mathrm{~h}$. This can be connected with strain hardening of particles during milling, but also with densification in the presence of liquid copper phase. Sintering processes are enhanced by the disturbances in the particles' crystal lattice caused by plastic deformation of powder particles during ball milling [13].

Increasing total amount of alloying additions enhanced hardenability of these steels [14]. Increase of manganese to $2 \%$ mass strongly increased tensile properties, but significantly decreased plastic properties. However, a combination of $1 \%$ mass $\mathrm{Mn}$ and $1 \%$ mass $\mathrm{Cu}$ had a significant effect on properties only after powder preparation in the ball mill. Melted $\mathrm{Cu}$ intensified sintering and densification processes through rearrangement of particles in the liquid phase. The higher amount of manganese overcame the densification effect of liquid $\mathrm{Cu}$ and caused no improvement of mechanical properties, or even their decrease. High amount of alloying additions caused decrease of plastic properties, however ball milling significantly improved this property. This effect is probably caused by revealing "fresh", oxygen-free, areas of particles which increase diffusion and chemical activity in those places. When the connections between particles were bigger, improving plasticity resulted. This phenomenon is very sensitive to the time of processing in the ball mill. After $2 \mathrm{~h}$ of milling, improvement was negligible. Yield tensile strength was ascertained based on ref [15], which also corresponds well with ref [16]. The YTS correlates with the same regularity as UTS. Steels based on $\mathrm{CrM}+1 \% \mathrm{Mn}+1 \% \mathrm{Cu}$ were characterized by a strong increase of HV 30 hardness from $\sim 190$ to $\sim 450$ as a function of milling time. That increase can be caused by strain hardening of particles during milling and by densification during sintering with the existence of a liquid phase.

The characteristic microstructures of research PM steels are shown on Fig. 11 and 14. Sinters were characterized by bainitic/martensitic microstructures which correspond well with plastic mechanical properties of examined sinters. There is also seen that microstructure of PM steels based on powders processed in ball mill for $1 \mathrm{~h}$ has got more "discreet and dispersive nature" of martensitic areas which are not well visible in 
comparison to all other variants. Chemical composition of research PM steels have got significant effect on microstructure.

The fractography of all PM steels variants are presented in Fig.15. For PM steels based on powder CrM $+1 \% \mathrm{Mn}$ processed in ball mill for $1 \mathrm{~h}$ and $2 \mathrm{~h}$ exhibits ductile areas characterized by dimples and failures in austenite. This can be explained by better particles connections after sintering operation which correspond well with elongation values of researched steels. In others researched PM steels, failure observations confirm mixed and brittle character of these materials. The highest amount of alloying additions increase hardenability of researched PM steels and favor forming of bainitic/martensitic microstructure. Failures of sinters based on powders processed for $2 \mathrm{~h}$ in ball mill characterized by the presence of oxides or other impurities [17]. PM steels based on powders with addition of $1 \%$ mass. of $\mathrm{Cu}$ characterized by mainly brittle failures. The coopers addition increased hardenability of researched steels and consequently in forming of more brittle areas.

\section{CONCLUSIONS}

Because of the high amount of alloying additions bainitic and martensitic microstructure occurred in all researched PM steels. In that case there is a need to provide tempering as additional heat treatment for gain better plastic properties. Powder processing by milling caused strain hardening and spheroidization of particles and in this effect, decrease compressibility. Strain hardened particles increase tensile properties in comparison to conventional processed PM steels. The fractography of researched steels correspond well with microstructures of sinters. Processing powders in ball mill for $1 \mathrm{~h}$ affected in increase of plastic properties of all alloy variants which is a sign of better connections between particles after sintering. A ball milling process caused an increase in activity of sintering processes by increasing of defects. Additional operation of ball milling of powders did not bring the expected results. Chemical composition of steels based on mixture $1 \%$ mass of $\mathrm{Mn}$ and $1 \%$ mass of $\mathrm{Cu}$ seems optimal for obtaining good mechanical properties, especially after proceeding in ball mill.

\section{Acknowledgement}

The financial support of the grant for Young Scientists under AGH contract no 15.11.110.427 is gratefully acknowledged.

\section{REFERENCES}

[1] Suryanarayana, C.: Progress in Materials Science, vol. 46, 2001, no. 1-2, p. 1

[2] Benjamin, JS., Volin, TE.: Metallurgical Transactions, vol. 5, 1974, p. 1929

[3] Tjong, SC., Chen, H.: Materials Science and Engineering R., vol. 45, 2004, p. 1

[4] Benjamin, JS.: Metal Powder Rep., vol. 45, 1990, p. 122

[5] Mei, QS., Lu, K.: Progress in Materials Science, vol. 52, 2007, p. 1175

[6] Sherif El-Eskandarany, M., Sumiyama, K., Suzuki, K.: Acta Materialia, vol. 45, 1997, p. 1175

[7] Zghal, S., Twesten, R., Wu, F., Bellon, P.: Acta Materialia, vol. 50, 2002, p. 4711

[8] Oleszak, D.: Acta Physica Polonica A, vol. 96, 1999, no. 1, p. 101

[9] Jurczyk, M.: Mechaniczna synteza. Poznań : Wyd. Politechniki Poznańskiej, 2003

[10] Metalog Guide, Struers, 2001

[11] Mukhtar, NZF., Borhan, Z., Rusop, M., Bin Adullah, S.: Advanced Materials Research, vol. 795, 2013, p. 711

[12] Parvin, N., Assadifard, R., Safarzadeh, P., Sheibani, S., Marashi, P.: Materials Science 
and Engineering A, vol. 492, 2008, p. 134

[13] Ciaś, A.: Private correspondence, 2017

[14] Daninger, H., Pöttschacher, R., Bradac, S., Šalak, A., Seyrkammer, J.: Powder Metallurgy, vol. 48, 2005, no. 1, p. 23

[15] Pavlina, EJ., Van Tyne, CJ.: Journal of Materials Engineering and Performance, vol. 17,2008 , no. 6 , p. 888

[16] MPIF Standard 352016 edition, 2016, p. 1-102

[17] Dudrová, E., Kabátová, M. In: Fractography of Sintered Materials Principles and Application - Workshop, 2015, p. 227 